\title{
Maternal Care and Attachment Security in Preschool Children*
}

\author{
Magaly Nóblega ${ }^{* *}$, Patricia Bárrig, \& Katherine Fourment \\ Ponti icia Universidad Católica del Perú, Lima, Perú
}

\begin{abstract}
This study assessed and compared the relationship between maternal sensitivity and child attachment in two groups of mother-child dyads from Lima, Peru, one group with children 4 years old and older and a second group with younger children. Fifty-six dyads participated in the study. The mothers ages ranged between 22 and 45 years $(M=33.14$, $S D=5.50) ; 82.1 \%$ of them had higher education and $73.2 \%$ were in a partner relationship. Of the children, 53.6 were boys and $41.1 \%$ were an only child. The study used AQS and MBPQS to rate child and maternal behavior respectively. Our results show a high correlation between attachment security and maternal sensitivity in both groups, as well as specific manifestations of these variables in the context studied.
\end{abstract}

KEYWORDS: attachment security, maternal sensitivity, preschooler

\section{Cuidado Materno e Apego em Crianças Pré-escolares}

RESUMO - O objetivo do presente estudo foi comparar a relação entre a qualidade da vinculação que as crianças estabelecem com a figura materna e a sensibilidade destas com filhos/as menores e maiores de 4 anos na cidade de Lima, Peru. Participaram 56 díades mãe-criança. A média de idades das mães é de 33,14 ( $D P=5,50), 82,1 \%$ tinham ensino superior, 73,2 \% estavam numa relação estável. 53,6\% das crianças eram do sexo masculino e 41.1\% filhos únicos. O AQS e o MBPQS foram utilizados para caracterizar os comportamentos de base segura das crianças e a sensibilidade materna. Constatou-se que a qualidade de vinculação está positiva e significativamente correlacionada com a sensibilidade materna. Estes resultados sugerem manifestações particulares do contexto peruano.

PALAVRAS-CHAVE: apego, sensibilidade materna, pré-escolar

\section{Cuidado Materno y Seguridad del Apego del Niño Preescolar}

RESUMEN - Se evaluó la relación entre la sensibilidad materna y la seguridad del apego del niño/a en diadas madreniño/a de Lima, Perú; esta relación se comparó entre díadas con hijos mayores y con hijos menores de 4 años. Participaron 56 díadas; las madres tenían entre 22 y 45 años $(M=33.14, D E=5.50), 82.1 \%$ reportó estudios superiores y $73.2 \%$ una relación de pareja; $53.6 \%$ fueron niños y $41.1 \%$ eran hijos únicos. Se utilizaron el AQS y el MBPQS para la calificación de la conducta del niño y de la madre respectivamente. Se halló una alta correlación entre ambas variables en ambos grupos. Se describen manifestaciones particulares de la seguridad del apego y la sensibilidad en el contexto estudiado.

PALABRAS CLAVE: seguridad del apego, sensibilidad materna, preescolares

The sensitivity hypothesis (Mesman, van IJzerdoorn, \& Sagi-Schwartz, 2016) about the relationship between the quality of maternal care (sensitivity) and a child's attachment security (secure base behavior) is one of the central tenets of attachment theory. This hypothesis posits that a mother's sensitive behavior organizes the child's secure base behavior (Bakermans-Kranenburg, van IJzendoorn, \& Juffer, 2003). The term secure base behavior refers to the interrelationship

\footnotetext{
* Support: Dirección General de Investigación - PUCP

** E-mail: mnoblega@pucp.pe

n Submetido: 03/09/2016; Revisado: 26/03/2018; Aceito: 02/09/2018.
} 
between the child's attachment behavior system and her or his exploratory behavior system (Cassidy, 2016). For the establishment of a secure attachment relationship, the child's main caregiver must foster exploration of the environment while functioning as a base to which the child can return when confronted with threats and uncertainties. (Bowlby, 1969/1982; Bretherton, 1992). Caregivers can fulfill such a role by optimizing their sensitivity, which is to say their ability to detect, interpret, and respond promptly and appropriately to the child's signals (Ainsworth, 1969). Thus, sensitive mothers are a source of confidence and security, and their children will be able to activate and deactivate exploratory and attachment behaviors. In turn, mothers who are less responsive to the child's signals, or who are unpredictable, may cause children to overly activate either their exploratory or their attachment behavior (Oliva, 2004).

In their pioneering study in Uganda, Ainsworth, Blehar, Waters, and Wall (1978) showed that there is a strong connection between maternal sensitivity and attachment security in children (.78, Goldsmith \& Alansky, 1987). However, many later studies have reported only weak or moderate connections (Atkinson et al., 2005; Behrens, Parker, \& Haltigan, 2011; De Wolff \& van IJzerdoorn, 1997; Nievar \& Becker, 2008). These results highlight the need to explore other relevant aspects of the relationship (Fearon \& Belsky, 2016; Kaloustian, 2004; Mesman et al., 2016), developmental and socio-cultural factors among them.

An awareness of the continuities and variations that occur in the mother-child attachment relationship depending on the child's age is particularly important (Sroufe, 2005). De Wolff and van IJzerdoorn (1997) and Atkinson et al. (2000) showed that the association is greater as the child's age increases. This can be explained by the child's sustained and continuous experience of sensitive maternal responses over time (Thompson, 1997). In assessing the influence of developmental aspects on secure base behavior, it has been said that the latter acquires a different character in the preschool stage, when autonomy and closeness to the attachment figure are equally relevant for the child (Marvin, Britner, \& Russell, 2016). In this context, children require less direct physical contact when close to the mother (Sroufe, 2005), and physical separation is eased. Additionally, the widening of the preschoolers' social world makes it possible for them to share pleasurable moments with adults other than the main attachment figure as well as with peers (Marvin \& Britner, 2008).

The influence of socio-cultural factors is also an important topic in attachment theory, given the evolutionary roots of its concepts (Bowlby, 1988), which demand constant assessment of the validity of its central hypotheses in different cultural contexts (Mesman et al., 2016). There are three positions regarding the universality of secure base behavior and sensitivity. One assumes it as a given on the basis of their phylogenetic roots (Bowlby, 1988) and the empirical evidence of their existence in a variety of contexts (Ainsworth et al., 1978). Other authors, in turn, believe that attachment and sensitivity manifest themselves differently in different cultures because of the specific meanings they acquire depending on the cultural context (e.g., Carlson \& Harwood, 2003; Kyoung, Jacobvitz, Hazen, \& Jung, 2012; Mizuta, 1996; Rothbaum, Kakinuma, Nagaoka, \& Azuma, 2007; Rothbaum, Weisz, Pott, Miyake, \& Morelli, 2000, 2001).

Finally, other authors, taking into account such cultural variations, describe secure base behavior as a universal phenomenon that responds to a biologically determined need to seek proximity and protection from a reliable figure, organized and expressed in culture-specific ways, and activated in culture-specific situations (e.g., Chao, 2001; Harwood, Miller, \& Irizarry, 1995; Posada \& Jacobs, 2001; Sagi-Schwartz, 1990; Mesman et al., 2017). Thus, variations have been described in the type of interactions that occur, the degree of proximity sought and provided, children's physical contact with their mothers, and their interactions with other adults in various contexts (Mesman et al., 2017; Posada, Gao, et al., 1995).

In the case of sensitivity, similar studies have not been carried out in a variety of countries. In Peru, Nóblega (2012) found that the optimal sensitivity described by experts and by the mothers themselves is closely aligned with that proposed by theory, while expectations for a sensitive mother's supervision and monitoring of their preschool-age children are lower.

With regards to the influence of cultural factors on the connection between secure base behavior and sensitivity, there are at least three clearly discernible schools of thought. One postulates that the relationship between these concepts is not applicable to every context, since their manifestations are different (Rothbaum et al., 2000, 2001). A second one sees a small relationship between sensitivity and secure base behavior in non-Western contexts (Mesman et al., 2016). A third position finds that the relationship remains as such across contexts if the specifics of attachment and sensitivity in each case are taken into account (Posada \& Jacobs, 2001). This last posture has found empirical support in studies carried out in Japan and Korea (Kyoung et al., 2012; Vereijken, Riksen-Walraven, \& Kondo-Ikemura, 1997); in Africa, even in conditions of extreme poverty or chronic illness (van IJzerdoorn et al. 2006); and in Latin America (Nóblega, 2012; Posada, Carbonell, Alzate, \& Plata, 2004; Posada, Jacobs, Carbonell, Alzate, Bustamante, \& Arenas, 1999; Posada et al., 2002; Valenzuela 1997).

Our study assessed the relationship between attachment security and maternal sensitivity in a group of preschool children in Lima and compared the results for the group of dyads with 4 year-old and older children with the results for the group with younger children. According to Posada and 
Jacobs (2001), a positive and significant link between the quality of maternal care and attachment security in children was to be expected, regardless of the different ways in which they may be expressed. Similarly, the link was expected to be stronger in dyads with older children. Our study also explored the characteristics of secure base behavior and sensitivity and compared them between the two groups, thus bringing into relief expressions that may reveal possible specificities of the mother-child relationship in the Peruvian context and the age-related variations.

\section{METHOD}

\section{Participants}

Fifty-six dyads comprised of a mother and her preschoolage child participated in this study. Participant mothers' ages ranged between 22 and 45 years $(M=33.14, S D=5.50)$; $82.1 \%$ of them had at least some college education, while the rest had completed secondary education. Also, $73.2 \%$ of mothers were in a cohabitation relationship and had between 1 and 3 children. $(M=1.84, S D=0.83)$. The average age for participating children was 52 months $(S D=11.72$, Min $=30, \operatorname{Max}=72) ; 53.6 \%$ of them were male and $41.1 \%$ were single children.

Based on the children's age, the dyads were grouped into two subsets: one subset comprised of 26 dyads with 30 - to 47-month-old children and an equal number of boys and girls, and a second set of 30 dyads with 49- to 72-month-old children, 17 of them boys and 13 girls. Both sets shared the same socio-cultural characteristics, having been recruited from the same area of residence. Also, there were no significant differences in the number of children per mother $(t(54)=0.59, p=.56)$, the mother's level of educational attainment $\left(X^{2}(1)=0.06, p=.80\right)$, or their relationship status $\left(X^{2}(1)=0.34, p=.56\right)$.

Besides the differences in children's ages $\left(M_{30 \text {-to } 47 \text {-month }}\right.$ dyads $=41.7, S D_{30 \text { - to } 47 \text {-month dyads }}=5.45, M_{49-\text { to } 72 \text {-month dyads }}=61$, $\left.S D_{49 \text { - to } 72 \text {-month dyads }}=7.52, t(54)=10.83, p<.001\right)$, another difference between the two groups were the mothers' ages $(M$ 30- to 47-month dyads $=31.04, S D_{30 \text { - to } 47 \text {-month dyads }}=4.47, M_{49}$ - to 72-month dyads $=34.97, S D_{49 \text { - to } 72 \text {-month dyads }}=5.72, t(54)=2.83, p=.01$ ).

The children in both groups attended a private preschool in Lima and did not display any evident developmental pathology such as mental retardation, autism, or Down syndrome. Participant mothers responded to a written invitation to volunteer for a study about the mother-child relationship, sent through their children's school.

\section{Measurement}

Secure base behavior. The organization of the secure base behavior was assessed using the Attachment Q-Set (AQS) version 3.0 (Waters, 1995). This measure uses a Q-Sort methodology, which involves ordering the 90 items that comprise it after the observation of the dyad in a natural context.

To obtain the level of attachment security for the child, the items' scores were correlated with the security criterion (Waters, 1995). Scores in the four dimensions describes by Posada, Waters, Crowell, and Lay (1995) were also obtained: Smooth Interactions with Mother, Proximity to Mother, Physical Contact with Mother, and Interactions with Other Adults. In this study, reliability indices by internal consistency of the scales for the total group were between .75 and .92; for the 30- to 47-month group, they fluctuated between .79 and .93; and for the 49- to 72-month group they were between .66 and .91. In both cases, Physical Contact with Mother was the scale with the lowest reliability (.79 and .66).

A number of studies have validated the security criterion in contexts other than the US, where it was initially established, including Peru (Cassibba, van IJzerdoorn, \& D Odorico, 2000; Nóblega, 2012; Posada et al. 1995; Posada et al., 2013).

Maternal sensitivity. The quality of maternal behavior in interaction with the child was measured using the Maternal Behavior for Preschoolers Q-Set (MBPQS) developed by Posada, Jacobs, and Richmond (Posada et al., 2007). This measure describes 90 maternal behaviors classified by an external observer after observing the mother in free interaction with her child. Like the AQS test, the MBPQS uses the Q-Sort methodology (Posada et al., 2007).

For the MBPQS' first level of analysis, the mother's global sensitivity was calculated by correlating the items' scores with the criterion (Posada et al. 2007), which has been validated for the Peruvian context (Nóblega, 2012). In a second level of analysis, scores were obtained for each of the sensitivity dimensions: Contributions to Harmonious Interactions; Secure-Base Support; Supervision/Monitoring; and Limit Setting. The reliability by internal consistency of the scales for both the whole group and each of the subsets ranged between .79 and .94 for all scales, with the exception of Limit Setting, which had a global reliability results of .57 , having obtained a reliability of .75 for the 30- to 47-month group and of .29 for the 49- to 72-month group. Earlier research (e.g., Posada et al., 2016) reported 
lower reliability for this scale and attributed it to the reduced number of items; in consequence, the scale will continue to be included in the analysis. The internal consistencies of the other scales in the instrument ranged between .74 and .94 for each of the groups.

\section{Procedure}

Data collection for this study took place at two different moments. Fieldwork with the 30- to 47-month dyads was carried out first; fieldwork with the older-child group came two years later. Research included two home visits with participants who agreed to participate voluntarily. During the first visit, a socio-demographic form was completed and then mother-child interactions were observed and recorded for periods between 60 and 120 minutes. These interactions were observed in the home, except for one that took place in a park as part of the dyad's daily routine. The secure base behavior and maternal sensitivity measures presented in this study are derived from these observations. The second visit was used to evaluate constructs that were included in other studies, such as ideal secure base behavior and sensitivity, children social competence, and others.

Observations of 36- to 47-months old children old were performed by a team of three psychologists or psychology graduates, while children 47- to 72-months old were observed by a team of 6 psychologists or psychology graduates. Of the total number of dyads, 46 were observed by two individuals present during observation and 10 had three observers; in half of the latter instances, the second and third evaluator assessments were based on video recordings of the interaction. Observers rating the child's behavior worked independently from those observing the mother in $82.15 \%$ of cases; in the remaining instances, the same observer team rated both child and mother.

This study's observers of children behavior were especially trained in attachment theory and in the use of the instrument, in the latter case both in its theoretical foundations and in the discussion and rating of three videos. In these training videos, participating observers obtained an average reliability of $.79(S D=0.03$, Min $=.75$, Max $=$ .84 ) before performing their scoring for the study proper.

For our study's scoring, average inter-observer reliability was initially $.77(S D=0.10, \operatorname{Min}=.51$ and $\operatorname{Max}=.95)$. As a second step, the scores for those items with large inter-observer discrepancies (a difference of over 3 points) were discussed, and this procedure raised the reliability. In consequence, no cases were discarded due to low interobserver reliability.

In that way, a consensus score was reached for those items. Thus, the observed secure base behavior for each child was comprised of the consensus score for the high- discrepancy items and the average of the observer's initial scores for the other items.

Observers of maternal behavior underwent training similar to that for AQS, and the average correlation between their scores of the three videos and the trainer's scores was $.81(S D=0.08, \operatorname{Min}=.64$ and $\operatorname{Max}=.89)$.

As was the case for the AQS, scoring of maternal behavior for the study proper took place in two stages (Posada et al., 2007). First, observers worked independently to score the interactions and obtained an average reliability of .72 $(S D=0.13$, Min $=.51$ and Max $=.93)$. In a second stage, items with highly discrepant scores (more than three points) were discussed, and a consensus was reached.

Mother's participation was strictly voluntary. After being appraised of the study's purpose and procedures, the potential risks and benefits, their right to decline to participate and to withdraw at any point, and the guaranteed confidentiality of any information collected by the researchers, each participant mother signed an informed consent form accepting her and her child's enrollment. All were also offered a final meeting with one of the researchers, intended to provide psychological guidance on childcare or child-rearing issues

\section{Data Analysis}

The analysis of the data collected was performed using the statistics package IBM-SPSS Statistics, version 19 (IBM Inc., 2010) and the G Power software, version 3.1.3 for calculating power (Faul, Erdfelder, Buchner, \& Lang, 2009). A preliminary analysis did not reveal any missing data and the team decided to retain the few atypical data that were found, understanding them to be representative of the phenomena under study and explained by the size of the participating group.

The correlation between levels of attachment security and sensitivity and its confidence interval were described using the Fisher $z$-transformation. Then, we performed a test to compare the correlation coefficients.

In the analysis of maternal sensibility dimensions and the child's attachment security, a comparison of the global configuration of the scales was performed using a multivariate analysis of variance (MANOVA), the magnitude of the differences (eta-squared), and the posthoc statistical power. Before performing the MANOVAs, multivariate normality assumptions were assessed based on univariate normality and the absence of atypical data calculated using the Mahalanobis distance. The homogeneity of the covariance matrices was assessed using Box's M test. To interpret the MANOVA we used Pillai's Trace to calculate $\mathrm{F}$, since it is especially robust for possible violation of assumptions in small samples (Field, 2005). 


\section{RESULTS}

Average attachment security in participating children was $.23(S D=0.26, \operatorname{Min}=-.38$, Max $=.67$, IC 95\% $=[.16$, .30]). Despite the great dispersion in the scores, it can be observed that only 8 out of the 56 children (14.29\%) obtained a negative score.

No significant differences were found in a comparison of the attachment security results for participating children in the 30- to 47-month group of dyads with those in the 49- to 72 -month group $\left(M_{30-47 \text { month }}=.20, S D=.27, M_{49-72 \text { month }}=\right.$ $.25, S D=.25, t(54)=.71, p=.48,1-\mathrm{b}=0.42)$. The MANOVA proved an absence of differences in the configuration of attachment security dimensions in both groups $(F(1,54)$ $\left.=0.97, p=.43, \mathrm{~h}^{2}=.07,1-\mathrm{b}=0.28\right)$. Figure 1 presents the similarities between the two groups' security dimensions and the differences with the theoretical level for each of them.
Maternal sensitivity for the whole group was .20 $(S D=.44, \operatorname{Min}=-.63, \operatorname{Max}=.78, I C 95 \%=[.08, .32])$. Descriptively, we observe that 18 mothers obtained negative values and 20 obtained sensitivity levels within the .5 to .8 range.

No significant differences in maternal behavior quality were found between the two groups ( $M$ mothers of $30-47$-month-old children $=.29, S D=.44, M$ mothers of $49-72$-month-old children $=.12$, $S D=.43, t(54)=1.52, p=.13,1-\mathrm{b}=.45)$. Similarly, the MANOVA revealed an absence of differences in the configuration of the dimensions of maternal behavior between the two groups $\left(F(4,51)=.707, p=.59, \mathrm{~h}^{2}=.05,1-\mathrm{b}\right.$ $=0.21)$. Figure 2 shows the similarities in the configuration of maternal behavior in both groups and how they compare with the theoretical value.

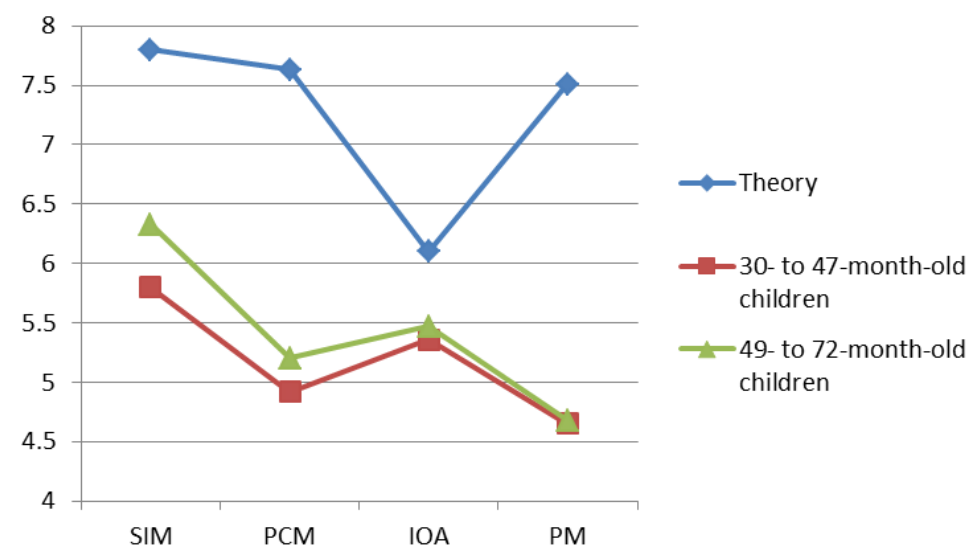

Figure 1. Dimensions of theoretical security in the group with 30- to 47-month old children and the group with 49- to 72-month old children Note. SIM $=$ Smooth Interactions with Mother, $\mathrm{PCM}=$ Physical Contact with Mother, IOA = Interactions with Other Adults, $\mathrm{PM}=$ Proximity to Mother.

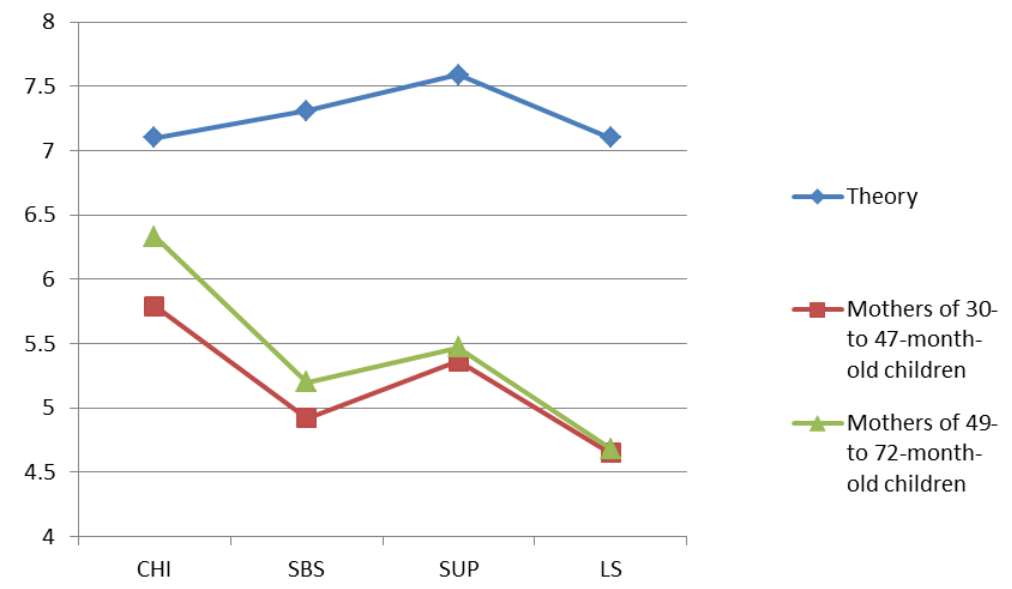

Figure 2. Dimensions of theoretical sensitivity in the group with 30- to 47-month old children and the group with 49- to 72-month old children Nota . $\mathrm{CHI}=$ Contribution to Harmonious Interactions, SBS $=$ Secure Base Support, SUP $=$ Supervision/Monitoring, LS = Limit Setting. 
With regards to the relationship between maternal sensitivity and attachment security in the child, the correlation for the whole group was $.59(p<.001$, IC 95\% $=[.39, .74])$. For the dyads with younger children, this association was $.54(p<.001, I C 95 \%=[.20, .77])$, while for the group of dyads with older children it was .66 ( $p<$ .001$, IC $95 \%=[.39, .82])$. The comparison of the groups' correlations shows that there are no significant differences $(z=0.42, p=.66)$.
Table 1 shows, for the whole group, the correlations between child's attachment security and its dimensions, between maternal sensitivity and its dimensions, and between the dimensions of maternal and child behavior. It also presents the internal consistency reliability scores for each scale.

Table 2 shows the intercorrelation matrix of attachment security, maternal sensitivity, and their dimensions for both groups of dyads.

Table 1

Intercorrelations and Alpha coefficients for the AQS and MBPQS scales for the whole group $(N=56)$

\begin{tabular}{|c|c|c|c|c|c|c|c|c|c|c|}
\hline Scale & SEC & SIM & РCM & IOA & PM & SEN & CHI & SBS & SUP & LS \\
\hline SEC & -- & & & & & & & & & \\
\hline SIM & $.87 * * *$ & $(.92)$ & & & & & & & & \\
\hline PCM & $.53 * * *$ & .24 & $(.75)$ & & & & & & & \\
\hline IOA & $.34^{*}$ & $.28 *$ & -.10 & (.89) & & & & & & \\
\hline PM & $.62 * * *$ & $.29 *$ & $.62 * * *$ & -.14 & $(.90)$ & & & & & \\
\hline SEN & $.59 * * *$ & $.34 *$ & .24 & .08 & $.51 * * *$ & -- & & & & \\
\hline CHI & $.48^{* * *}$ & $.30^{*}$ & .24 & .09 & $.50 * * *$ & $.98 * * *$ & $(.94)$ & & & \\
\hline SBS & $.50 * * *$ & $.30 *$ & $.32 *$ & .08 & $.56 * * *$ & $.92 * * *$ & $.93 * * *$ & $(.92)$ & & \\
\hline SUP & $.53 * * *$ & $.36^{* *}$ & .20 & .02 & $.57 * * *$ & $.84 * * *$ & $.81 * * *$ & $.78 * * *$ & $(.79)$ & \\
\hline LS & $.41 * *$ & $.41 * *$ & .16 & -.04 & .22 & $.65^{* * *}$ & $.59 * *$ & $.48 * * *$ & $.51 * * *$ & $(.57)$ \\
\hline
\end{tabular}

Note. SEC $=$ Attachment Security, $\mathrm{SIM}=$ Smooth Interactions with Mother, PCM $=$ Physical Contact with Mother, IOA = Interactions with Other Adults, $\mathrm{PM}=$ Proximity to Mother, $\mathrm{SEN}=$ Sensitivity, $\mathrm{CHI}=$ Contribution to Harmonious Interactions, $\mathrm{SBS}=$ Secure Base Support, $\mathrm{SUP}=\mathrm{Supervision} /$ Monitoring, LS $=$ Limit Setting ${ }^{*} p<.05, * * p<.01, * * * p<.001$

Table 2

Intercorrelations of the AQS and MBPQS scales for the groups with 30- to 47-month-old children $(n=26)$ and he group with 49- to 72-month-old children $(n=30)$

\begin{tabular}{|c|c|c|c|c|c|c|c|c|c|c|}
\hline Scale & SEC & SIM & PCM & IOA & $\mathbf{P M}$ & SEN & $\mathrm{CHI}$ & SBS & SUP & LS \\
\hline SEC & -- & $.88 * * *$ & $.51^{* *}$ & .18 & $.68 * * *$ & $.54 * * *$ & $.45^{* *}$ & $.47^{*}$ & $.51^{* *}$ & .38 \\
\hline SIM & $.87 * * *$ & - & .19 & .14 & .37 & .27 & .24 & .21 & .27 & $.46^{*}$ \\
\hline PCM & $.56^{* *}$ & .27 & -- & -.17 & $.64 * * *$ & .33 & .38 & $.47 *$ & .31 & .09 \\
\hline IOA & $.51^{* *}$ & $.45^{*}$ & -.02 & -- & .25 & -.23 & -.22 & -.20 & -.20 & -.25 \\
\hline PM & $.56^{* *}$ & .21 & $.65 * * *$ & -.02 & -- & $.65^{* * *}$ & $.66^{* * *}$ & $.75^{* * *}$ & $.66^{* * *}$ & .22 \\
\hline SEN & $.66^{* * *}$ & $.52 * *$ & .22 & $.41 *$ & $.41^{*}$ & -- & $.97 * * *$ & $.91 * * *$ & $.84 * * *$ & $.71^{* * * *}$ \\
\hline $\mathrm{CHI}$ & $.56^{* *}$ & $.46^{*}$ & .17 & $.39 *$ & $.38 *$ & $.98 * * *$ & -- & $.93 * * *$ & $.79 * * *$ & $.66^{* * *}$ \\
\hline SBS & $.58^{* *}$ & $.49 * *$ & .28 & .33 & $.45^{*}$ & $.93 * * *$ & $.92 * * *$ & -- & $.79 * * *$ & $.48^{*}$ \\
\hline SUP & $.60^{* * *}$ & $.54 * *$ & .10 & .26 & $.50^{* *}$ & $.84 * * *$ & $.83 * * *$ & $.78 * * *$ & -- & $.54 * *$ \\
\hline LS & $.46^{*}$ & $.38^{*}$ & .30 & .24 & .22 & $.61 * * *$ & $.55^{* * *}$ & $.51 * *$ & $.48^{* *}$ & -- \\
\hline
\end{tabular}

Note. $\mathrm{SEC}=$ Attachment Security, $\mathrm{SIM}=$ Smooth Interactions with Mother, $\mathrm{PCM}=$ Physical Contact with Mother, IOA $=$ Interactions with Other Adults, $\mathrm{PM}=$ Proximity to Mother, $\mathrm{SEN}=$ Sensitivity, $\mathrm{CHI}=$ Contribution to Harmonious Interactions, $\mathrm{SBS}=$ Secure Base Support, SUP $=$ Supervision/ Monitoring, LS = Limit Setting

Intercorrelations for 30- to 47 -month dyads are presented above the diagonal, and intercorrelations for 49 - to 72 -month dyads are presented below the diagonal.

$* p<.05, * * p<.01, * * * p<.001$ 


\section{DISCUSSION}

The purpose of this study was to assess the relationship between attachment security in preschool children and maternal sensitivity, and to describe the manifestations of both secure base behavior and maternal behavior quality in a specific context. Also, in order to identify evolutionary continuities and variations in the mother-child relationship in the preschool period (Sroufe, 2005), we compared this relationship in two groups, one with 30- to 47-month-old children and one with 49- to 72-month-old children. Finally, we intended to describe the characteristics of secure base behavior and sensitivity in both groups of dyads.

We found that in the whole sample of children, levels of security are lower than the results of other studies in Latin America (Posada et al., 1999; Posada et al., 2002; Posada et al., 2004), yet similar to those reported in two previous studies in Peru (Buitrón, 2008; Pedraglio, 2002). It is possible to hypothesize that children in the Peruvian context tend to have lower levels of attachment security, but the high variability in this study's results means that further research is needed to corroborate that assertion.

In terms of their comparison with the theoretical levels, the expectation was not for observed values to be similar to the criteria establishes in the theory, so we will discuss those dimensions where the difference with those criteria was smaller or greater. The greatest difference is that children in this study show less proximity-seeking behaviors; at the same time, they obtained lower scores in their enjoyment of physical contact with mother. These results appear to confirm preschool children's lower levels of physical contact with mother described by Marvin and Greenberg (1982).

On the other hand, the smallest difference found between observed and theoretical values for the whole sample was in the dimension of interaction with other adults. This finding can be explained by the ideal socialization in Latin American and Peruvian contexts, where children are expected to be well disposed towards others, respectful, and polite to their elders (Halgunseth, Ispa, \& Rudy, 2006; Nóblega, Thorne, Peña, \& Moreyra, 2009).

It is worth noting there are no differences in these characteristics between the two age groups; thus, they may be evidence of the ways in which preschool-age children relate to their mothers.

In terms of the association between the secure base behavior dimensions in the whole sample, we found that proximity-seeking is strongly associated with the child's enjoyment of physical contact with mother. This is evidence that, independent of the child's age, the use of the mother as a secure base and as a source of physical enjoyment are connected to the establishment of secure base behavior. At the same time, we observed a connection between the smoothness in the mother-child interaction and the child's proximity-seeking, which is consistent with the theory; however, since this connection is significant only for the whole sample, our results will need to be contrasted with those of later studies.

For the whole group, we also found that the child's interactions with other adults are also associated with the dimension of smooth interactions with mother; this association, however, obtains only for the group with older children, while interaction with other adults remains relatively independent for younger children. It is possible that in this context, interaction with other adults is part of attachment security in older children, which may respond to socio-cultural beliefs in Latin America and Peru about the relationship between children and adults, as noted above.

Observed values for maternal sensitivity in both groups are also lower than those reported in other Latin American studies (Posada et al., 1999; Posada et al., 2002; Posada et al., 2004). It is worth noting in this connection, as in the case of attachment security in children, that while this could be seen as a maternal sensitivity tendency in the context, further research is needed given the high dispersion of the scores obtained by the participants in our study.

Nevertheless, such lower levels of maternal sensitivity could be interpreted on the basis of beliefs and expectations prevalent among mothers of preschool-age children in the Latin American context. Children in Latin America are perceived as more resourceful and are expected to be more independent at around the age of 6 (Halgunseth et al., 2006). As a result, mothers may be less intensely alert to their activities and may interact with them less often. This could be a feature of the entire preschool period, as indicated by the close alignment between the two maternal groups in our study. The low maternal sensitivity scores independently of the children's ages could also be explained as an expression of specific modes of the mother-should relationship not included in the MBPQS' maternal-behavior profile, given that some maternal behaviors can be particular to their context (Carlson \& Harwood, 2003; Harwood et al., 1995; Harwood et al., 1996; Rothbaum et al., 2000, 2001). Another factor take into account is that our study focused exclusively on the preschool stage; the narrow range of children's ages may have resulted in evidence of continuity in maternal behavior during the preschool period, rather than of discontinuity.

Comparing maternal behavior in our study with theoretical values, we found the greatest divergence in the mother's sensitive supervision of children. This finding can be explained by the expectation, in Latin American contexts, for mothers to exercise control over and direct their children (Bornstein \& Cote, 2001; Cote \& Bornstein, 2001; Carlson \& Harwood, 2003; Domenech-Rodriguez, 
Donovick, \& Crowley, 2009; Fischer, Harvey, \& Driscoll, 2009; Halgunseth et al., 2006) in order raise them as "obedient" (Gonzales-Ramos, Zayas, \& Cohen, 1998) and "polite" (Nóblega et al., 2009).

Analyzing the consistency of maternal behavior, our study also found that the four dimensions of maternal sensitivity are strongly interrelated, both for the whole sample and the two subsets as predicted by the theory. For this reason, when mothers contribute to the smoothness of their interactions with their children, they function as a secure base and have a sensitive way to supervise and to set limits to their behavior. However, internal consistency for the limit setting scale was low. While this aligns with previously reported results, it could be a reflection of the tendency, in Latin American contexts that emphasize such aspects as respect and obedience, to establish sensitive limits in unconscious ways. Further research into this hypothesis is recommended.

Finally, in connection with this study's main purpose, our results show a positive and significant relationship between secure base behavior and maternal sensitivity for the whole group and for each of the two subsets. This finding provides evidence for the sensitivity hypothesis in this context (van Ijzerdoorn et al., 2006) and highlights the organizational character of attachment during the preschool period, despite the variations derived from the developmental process. It also gives empirical support to the universality of the relationship (Gjerde, 2001; Kondo-Ikemura, 2001; Posada, Gao et al., 1995; Posada \& Jacobs, 2001; Rothbaum et al., 2007; van IJzerdoorn \& Sagi-Schwartz, 2001, 2008). The absence of significant differences between the correlations found for the two groups of dyads in our study reinforce the postulate of maternal care as an organizer of children's behavior throughout the preschool period (Marrone, 2001). Thus, as a main attachment figure, a child's mother would be his or her main source of confidence and comfort, a key element in healthy development (Bowlby, 1988; Coleman \& Watson, 2000; Marrone, 2001; Oliva, 2004; van IJzerdoorn \& Sagi-Schwartz, 2008).

Some methodological considerations may provide an explanation for these results, among them the use of observations in natural environment rated by the same method (Ainsworth et al., 1978; Posada et al., 1999; Posada et al., 2002; Posada et al., 2004) and the simultaneous observation of both behaviors (Atkinson et al, 2000; De Wolff \& van IJzerdoorn, 1997). It also bears pointing out that the independence of the observers in a large percentage of cases ameliorates any bias that may emerge during scoring, due to the intervention of a same observer or child and mother.

For both the whole sample and each of the two age-based groups, we found that the children engage in harmonious interactions with their mothers when the latter contribute to smooth interactions, fulfill the role of a secure base while encouraging exploration, supervise the child's activities sensitively, and establish norms and limits. This shows that sensitive maternal behavior is met with a warm response from children.

Meanwhile, children in both groups who used their mother as a secure base had mothers who interacted harmoniously with them, encouraged exploration, and balanced the tasks of supervising and participating in their children's activities. This may allow us to conclude that sensitive mothers promote their use by their children as a secure base from which to engage in exploratory behaviors.

Finally, the child's enjoyment of physical contact with mother was associated, for the whole sample, with the mother's provision of secure base support, albeit this result was obtained only with the $30-$ to 47 -month group. This finding can be explained by the importance that physical contact has before the age of 4 (Sroufe, 2005), which in this case is connected with the mother's availability to her child's contact requests.

As a whole, our study's results provide evidence in support of the main hypotheses of attachment theory and suggest that attachment and maternal care systems organized in a reciprocal manner (Bowlby, 1969/1982; Sroufe, 2005) during the entire preschool-age period. They also provide empirical support to Posada's and Jacob's (2001) assertion of a high positive relationship between the two concepts even when their characteristics are specific to the context under study, as evidenced also in previous studies in Asian (Vereijken et al., 1997), African (van IJzerdoorn et al., 2006) and Latin American contexts (Posada et al., 1999; Posada et al., 2002; Posada et al., 2004; Valenzuela, 1997).

While these results support the relevance of the sensitivity hypothesis in the Peruvian context, the task of corroborating this study's findings with further research that replicates them or delves deeper into the expression of behaviors in the mother-child relationship.

In conclusion, this study is a reference for understanding of the nature of the mother-child relationship in a context other than the one where attachment theory was first developed, and for describing ethno-theories of maternal care and preschool children behavior in that context. A deeper understanding of the mother-child relationship contributes to the design of early interventions on emotional aspects of the maternal role, intended to promote healthy development in children. This acquires even greater value if we consider the importance of early relationships in the prevention of processes now seen as key for the emergence of lifelong psychopathologies. 


\section{REFERENCES}

Ainsworth, M. (1969). Ainsworth Maternal Sensitivity Scales - John Hopkins University. Retrieved from http://www.psychology. sunysb.edu/attachment/pdf/mda_sens_coop.pdf

Ainsworth, M., Blehar, M., Waters, E. \& Wall, S. (1978). Patterns of attachment. A psychological study of the Strange Situation. New Jersey: Lawrence Erlbaum Associates.

Atkinson, L., Goldberg, S., Raval, V., Pederson, D., Benoit, D., Moran, G., ... Leung, E. (2005). On the relation between maternal state of mind and sensitivity in the prediction of infant attachment security. Developmental Psychology, 41, 42-53

Atkinson, L., Niccols, A., Paglia, A., Coolbear, J., Parker, K., Poulton, K., ... Sitarenios, G. (2000). A Meta-analysis of time between maternal sensitivity and attachment assesments: Implications for internal working models in infancy/ toddlerhood. Journal of Social and Personal Relationships, $17,791-810$

Bakermans-Kranenburg, M. J., Van IJzendoorn, M. H., \& Juffer, F. (2003). Less is more: Metaanalyses of sensitivity and attachment interventions in early childhood. Psychological Bulletin, 129, 195-215. doi: 10.1037/0033-2909.129.2.195

Behrens, K. Y., Parker, A. C., \& Haltigan, J. D. (2011). Maternal sensitivity assessed during the Strange Situation Procedure predicts child's attachment quality and reunion behaviors. Infant Behavior and Development, 34, 378-381

Bornstein, M., \& Cote, L. (2001). Mother-infant interaction and acculturation: I. Behavioural comparisons in Japanese American and South American families. International Journal of Behavioral Development, 25, 549-563. doi: 10.1080/01650250042000546

Bowlby, J. (1969/1982). Attachment and loss: Vol 1. Attachment. New York: Basic Books.

Bowlby, J. (1988). A secure base. Parent-child attachment and healthy human development. London: Routledge.

Bretherton, I. (1992). The origins of attachment theory: John Bowlby and Mary Ainsworth. Developmental Psychology, 28, 759-775. doi: http://dx.doi.org/10.1037/0012-1649.28.5.759

Buitrón, V. (2008). Apego en hijos de madres adolescentes víctimas de abuso sexual en Lima Metropolitana (Degree Thesis). Pontificia Universidad Católica del Perú, Lima, Peru.

Carlson, V., \& Harwood, R. (2003). Attachment, culture and the caregiving system: The cultural patterning of everyday experiences among Anglo and Puerto Rican mothers-infant pairs. Infant Mental Health Journal, 24(1), 53-73.

Cassidy, J. (2016). The nature of the child's ties. In J. Cassidy \& P. R. Shaver (Eds.), Handbook of attachment: Theory, research, and clinical applications ( ${ }^{\text {rd }}$. ed., pp. 3-24). New York: Guilford.

Cassibba, R., van IJzerdoorn, M., \& D'Odorico, L. (2000). Attachment and play in child care centers: Reliability and validity of the attachment Q-Sort for mothers and professional caregivers in Italy. International Journal of Behavioral Development, 24, 241-255. doi: 10.1080/016502500383377

Chao, R. (2001). Integrating culture and attachment. American Psychologist, 56(10), 822-823.

Coleman, P., \& Watson, A. (2000). Infant attachment as a dynamic system. Human Development, 43(6), 295-313.

Cote, L., \& Borstein, M. (2001). Mother-infant interaction and acculturation: II. Behavioural coherence and correspondence in Japanese American and South American families. International Journal of Behavioral Development, 25(6), 564-576.

De Wolff, M., \& van IJzendoorn, M. (1997). Sensitivity and attachment: A meta-analysis on parental antecedents of infant attachment. Child Development, 68(4), 571-591. doi: $10.2307 / 1132107$

DeKlyen, M., \& Grenberg, M. (2008). Attachment and psychopathology in childhhod. In J. Cassidy \& P. Shaver
(Eds.), Handbook of attachment. Theory, research, and clinical applications (2a ed., pp. 637-665). New York: The Guilford Press.

Domenech-Rodríguez, M., Donovick, M., \& Crowley, S. (2009). Parenting styles in a cultural context: Observations of "Protective Parenting" in first-generation Latinos. Family Process, 48(2), 195-210. doi: 10.1111/j.15455300.2009.01277.x

Faul, F., Erdfelder, E., Buchner, A., \& Lang, A. (2009). Statistical power analyses using $\mathrm{G}^{*}$ Power 3.1: Tests for correlation and regression analyses. Behavior Research Methods, 41, 11491160.

Fearon, P., \& Belsky, J. (2016). Precursors of Attachment Security. In J. Cassidy \& P. R. Shaver (Eds.), Handbook of attachment: Theory, research, and clinical applications (3rd ed., pp. 291-313). New York: Guilford.

Field, A. P. (2009). Discovering statistics using SPSS. London: SAGE.

Fischer, C., Harvey E., \& Driscoll P. (2009). Parent-centered parenting values among Latino immigrant mothers. Journal of Family Studies, 15(3), 296-308.

Gjerde, P. (2001). Attachment, culture and amae. American Psychologist, 56(10), 826-827.

Goldsmith, H., \& Alansky, J. (1987). Maternal and infant temperamental predictors of attachment: A meta-analytic review. Journal of Consulting and Clinical Psychology, 55(6), 805-816. doi:10.1037/0022-006X.55.6.805

Gonzales-Ramos, G., Zayas, L., \& Cohen, E. (1998). Child-rearing values of low-income, urban Puerto Rican mothers of preschool children. Professional Psychology: Research and Practice, 29, 377-382.

Halgunseth, L., Ispa, J., \& Rudy, D. (2006). Parental control in Latino families: An integrated review of the literature. Child Development, 77, 1282-1297. doi: 10.1111/j.14678624.2006.00934.x

Harwood, R., Miller, J., \& Irizarry, L. (1995). Culture and attachment: Perceptions of the child in context. New York: The Guilford Press.

Harwood, R., Schoelmerich, A., Ventura-Cook, E., Schulze, P., \& Wilson, S. (1996). Culture and class influences on Anglo and Puerto Rican mothers' beliefs regarding long-term socialization goals and child behavior. Child Development, 67, 2446-2461. doi: 10.1111/j.1467-8624.1996.tb01867.x

IBM, Inc. (2010). SPSS Statistics. Versión 19.

Kaloustian, G. (2004). Maternal mental representations and sensitivity in mother-child attachment relationships. (Master's Thesis). Purdue University, Indiana, United States of America.

Kondo-Ikemura, K. (2001). Insufficient evidence. American Psychologist, 56(10), 825-826.

Kyoung, M., Jacobvitz, D., Hazen, N., \& Jung, S. (2012). Maternal sensitivity and infant attachment security in Korea: Crosscultural validation of the Strange Situation. Attachment \& Human Development, 14(1), 33-44.

Marrone, M. (2001). La teoría del apego: Un enfoque actual. Madrid, Spain: Lugar Editorial.

Marvin, R. S., Britner, P. A., \& Russell, B. S. (2016). Normative development: The ontogeny of attachment in childhood. In J. Cassidy \& P. R. Shaver (Eds.), Handbook of attachment: Theory, research, and clinical applications (3rd ed., pp. 273-2907). New York: Guilford.

Mesman, J., Van IJzendoorn, M. H., \& Sagi-Schwartz, A. (2016). Cross-cultural patterns of attachment: Universal and contextual dimensions. In J. Cassidy \& P. R. Shaver (Eds.), Handbook of attachment: Theory, research, and clinical applications (3rd ed., pp. 852-877). New York: Guilford. 
Mesman, J., Minter, T., Angnged, A., Cissé, I., Salali, G. G., \& Migliano, A. B. (2017). Universality without uniformity: A culturally inclusive approach to sensitive responsiveness in infant caregiving. Child Development, 89(3), 837-850. doi: 10.1111/cdev.12795

Mizuta, I. (1996). Cross-cultural study of preschoolers' attachment: Security and sensitivity in Japanese and US dyads. International Journal of Behavioral Development, 19(1), 141-160.

Nievar, M., \& Becker, B. (2008). Sensitivity as a privileged predictor of attachment: A second perspective on De Wolff and van IJzendoorn's meta-analysis. Social Development, $17(1), 102-114$

Nóblega, M. (2012). Conducta de base segura y sensibilidad en niños y madres del distrito de Los Olivos (Doctoral Dissertation). Pontificia Universidad Católica del Perú, Lima, Peru.

Nóblega, M., Thorne, C., Peña, B., \& Moreyra, P. (2009). Imágenes de la niñez desde la perspectiva de las madres peruanas. Revista de Psicología PUCP, 29(2), 213-242.

Oliva, A. (2004). Estado actual de la teoría del apego. Revista de Psiquiatría y Psicología del Niño y el Adolescente, 4(1), 65-81.

Pedraglio, C. (2002). Apego en niños de madres que trabajan (Degree Thesis). Pontificia Universidad Católica del Perú, Lima, Peru.

Posada, G., Carbonell, O., Alzate, G., \& Plata, S. (2004). Through Colombian lenses: Etnographic and conventional analysis of maternal care and their associations with secure base behavior. Developmental Psychology, 40, 508-518.

Posada, G., Gao, Y., Wu, F., Posada, R., Tascon, M., Schöelmerich, A., Sagi-Schwartz, A., Kondo-Ikemura, K., Haaland, W. \& Synnevaag, B. (1995). The secure-base phenomenon across cultures: children's behavior, mother's preferences, and expert's concepts. In E. Waters, B. Vaughn, G. Posada, \& K. Kondo-Ikemura (Eds), Caregiving, cultural and cognitive perspectives on secure-base behavior and working models. New Growing Points of Attachment Theory and Research. Monographs of the Society for Research in Child Development, 60(2-3, Serie 244, pp. 27-48).

Posada, G., \& Jacobs, A. (2001). Child-mother attachment relationships and culture. American Psychologist, 56(10), 821-822.

Posada, G., Jacobs, A., Carbonell, O., Alzate, G., Bustamante, M., \& Arenas, A. (1999). Maternal care and attachment security in ordinary and emergency contexts. Developmental Psychology, $35,1379-1388$.

Posada, G., Jacobs, A., Richmond, M., Carbonell, O., Alzate, G., Bustamante, M., \& Quiceno, J. (2002). Maternal caregiving and infant security in two cultures. Developmental Psychology, $38,67-78$.

Posada, G., Kaloustian, G., Richmond, M., \& Moreno, A. (2007). Maternal secure base support and preschoolers' secure base behavior in natural environments. Attachment \& Human Development, 9(4), 393-411. doi: 10.1080/14616730701712316

Posada, G., Lu, T., Trumbell, J., Kaloustian, G., Trudel, M., Plata, S. J., Peña, P. P., ... Lay, K.-L. (2013). Is the secure base phenomenon evident here, there, and anywhere? A cross- cultural study of child behavior and experts' definitions. Child Development, 84, 1896-1905. doi: 10.1111/cdev.12084

Posada, G., Waters, E., Crowell, J., \& Lay, K. (1995). Is it easier to use secure mother as a secure base? Attachment Q-sort correlates of the Adult Attachment Interview. In E. Waters, B. Vanghn, G. Posada, \& K. Kondo - Ikemura (Eds.), Caregiving, cultural and cognitive perspectives on secure - base behavior and working models. New Growing Points of Attachment Theory and Research. Monographs of the Society for Research in Child Development, 60(2-3 Serie 244, pp. 133-178).

Rothbaum, F., Kakinuma, M., Nagaoka, R., \& Azuma, H. (2007). Attachment and AMAE: Parent-child closeness in the United States and Japan. Journal of Cross-Cultural Psychology, 38(4), 465-486. doi: 10.1177/0022022107302315

Rothbaum, F., Weisz, J., Pott, M., Miyake, K., \& Morelli, G. (2000). Attachment and culture. Security in the United States and Japan. American Psychologist, 55(10), 1093-1104.

Rothbaum, F., Weisz, J., Pott, M., Miyake, K. \& Morelli, G. (2001). Deeper into attachment and culture. American Psychologist, 56(10), 827-829.

Sagi-Schwartz, A. (1990). Attachment theory and research from cross-cultural perspective. Human Development, 33, 10-22.

Sroufe, L. A. (2005). Attachment and development. A prospective, longitudinal study from birth to adulthood. Attachment \& Human Development, 7(4), 349-367. doi: $10.1080 / 14616730500365928$

Thompson, R. A. (1997). Sensitivity and security: New questions to ponder. Child Development, 68, 595-597. doi: 10.1111/j.14678624.1997.tb04220.x

Valenzuela, M. (1997). Maternal sensitivity in a developing society: The context of urban poverty and infant chronic undernutrition. Developmental Psychology, 33(5), 845-855.

van IJzerdoorn, M., Bakermans-Kranenburg, M., \& Sagi-Schwartz, A. (2006). Attachment across diverse sociocultural contexts: The limits of universality. En K. Rubin \& O. Boon (Eds.), Parenting Beliefs, Behaviors and Parent-Child Relations (pp. 107-142). Nueva York: Psychology Press.

van IJzendoorn, M., \& Sagi-Schwartz, A. (2001). Cultural blindness or selective inattention? American Psychologist, 56(10), 824825 .

van IJzendoorn, M., \& Sagi-Schwartz, A. (2008). Cross-cultural patterns of attachment: Universal and contextual dimensions. In J. Cassidy \& P. Shaver (Eds.), Handbook of Attachment. Theory, Research and Clinical Applications (2a ed., pp. 880905). New York: Guilford Press.

Vereijken, C., Riksen-Walraven, M., \& Kondo Ikemura, K. (1997). Maternal sensitivity and infant attachment security in Japan: A longitudinal study. International Journal of Behavioral Development, 21, 35-49.

Waters, E. (1995). The attachment Q Set. In E. Waters, B. Vaughn, G. Posada, \& K. Kondo-Ikemura (Eds.), Caregiving, cultural, and cognitive perspectives on secure base behavior and working models: New growing points of attachment theory and research. Monographs of the Society for Research in Child Development 60(2-3, Serie 244, 234-246). 


\section{ERRATUM}

Regarding the article "Maternal Care and Attachment Security in Preschool Children", with DOI number: http://dx.doi. org/10.1590/0102.3772e3534</ext-link>, published in Psicologia: Teoria \& Pesquisa, vol 35, elocation e3534:

Where was written:

Katherine Fourmen

Now read:

Katherine Fourment 